\title{
APLICACIÓN DE LOS PROCESOS SINÓPTICOS OBJETIVOS A LA PENÍNSULA IBÉRICA EN OTOÑO
}

\author{
Antonio de Jesús Fernández García \\ Centro Meteorológico Provincial de Cienfuegos (Cuba) \\ Javier Martín Vide \\ Grupo de Climatología, Universidad de Barcelona \\ Yosvanis Armando Díaz Pérez \\ Centro Meteorológico Provincial de Cienfuegos (Cuba) \\ Antonio Mestre Barceló \\ Instituto Nacional de Meteorología, Madrid
}

\section{RESUMEN}

En el artículo se aplica la clasificación objetiva de los llamados Procesos Sinópticos Objetivos (PSO) de Fernández y Díaz (2003), basada en la presión atmosférica en superficie y el geopotencial en $500 \mathrm{hPa}$ en su evolución temporal durante 3 días, al territorio peninsular de España y las islas Baleares. Se señalan las ventajas de esta clasificación sobre las subjetivas o manuales y su capacidad para reflejar adecuadamente los tipos atmosféricos que influyen en el área de estudio durante los meses otoñales. En concreto, la diversidad sinóptica del área durante el bimestre septiembre-octubre se resume en 20 PSOs, para los que se calcula su frecuencia y período de retorno. Las características de cada PSO se ponen en relación con la probabilidad de ocurrencia de precipitación y su cantidad media diaria.

Palabras clave: clasificación sinóptica, Baleares, España peninsular, precipitación, Proceso Sinóptico Objetivo, tipo de tiempo.

\section{ABSTRACT}

The objective weather-type system of Synoptic Objective Processes (PSO) by Fernández y Díaz (2003), based on surface atmospheric pressure and $500 \mathrm{hPa}$ topography according their temporal evolution along 3 days, has been applied to the Peninsular Spain and Balearic Islands. The advantages of this classification respect to the subjective ones and its capacity to reflect suitably the weather-types influencing over the study area in fall are exposed. The synoptic diversity of the area during the months of September and October are summarized by means of 20 PSOs. Their frequency and return period are 
calculated. The features of each PSO are put in relation with the probability of rain ant its daily mean amount.

Key words: Balearic Islands, Peninsular Spain, precipitation, Objective Synoptic Processes, weather-type, weather-type system.

\section{Introducción}

El clima de cada rincón del planeta viene caracterizado por la influencia de determinados patrones atmosféricos. Las variables o elementos climáticos están condicionados por los mecanismos de la circulación atmosférica. Ello aconseja el estudio simultáneo de los procesos de la circulación atmosférica y el comportamiento de las variables climáticas, con una concepción del clima que hace complementarios los métodos sintético-sinóptico y analítico (Gil Olcina y Olcina, 1997). En esta dirección es muy útil el empleo de las clasificaciones de situaciones sinópticas, ya que permiten asociar los tipos de tiempo que producen con valores particulares de las variables climáticas en cada región. Se distingue de entrada, por tanto, entre situación sinóptica y tipo de tiempo, de manera que una determinada situación sinóptica afectando a toda la España peninsular produce con frecuencia varios tipos de tiempo, dependiendo de la región o lugar, que pueden diferir notablemente entre sí (MartínVide, 1991).

La inexistencia de una clasificación de situaciones sinópticas general y de amplia aceptación para la Península Ibérica constituye un obstáculo con el que se enfrenta el climatólogo en este ámbito europeo entre la zona templada y la subtropical. En España cada investigador, dependiendo de la naturaleza y objeto de su estudio, ha debido elaborar su propia clasificación de situaciones sinópticas, casi siempre basada en criterios subjetivos. La inexistencia de una clasificación sinóptica generalmente aceptada deriva de la propia complejidad atmosférica del país, donde a menudo el campo bárico superficial está poco definido o no presenta concordancia con niveles superiores, e, incluso, de su notable extensión, que permite la ocurrencia al tiempo de varias situaciones distintas en diferentes regiones. Entre los catálogos de situaciones sinópticas más generales están los propuestos por Linés (1981), con 25 tipos en $300 \mathrm{hPa}$, Font Tullot (1983), con 23 tipos que combinan superficie y $500 \mathrm{hPa}$, Martín Vide (1991), con 16 tipos usando los mismos niveles, y Capel Molina (2000), con 18 tipos basados en superficie y en 500 ó $300 \mathrm{hPa}$. Se trata en todos los casos de clasificaciones subjetivas o manuales.

En consecuencia, resulta de una notable necesidad e interés avanzar en la búsqueda de una clasificación sinóptica para la Península Ibérica que pueda ser aceptada ampliamente. Tal tarea no parece posible usando criterios subjetivos. Las clasificaciones objetivas o automáticas constituyen, metodológicamente, la vía idónea para encontrar una solución aceptable con generalidad, aunque algunas de las más conocidas, como la de Jenkinson y Collison (1977), presentan limitaciones al ser exportadas al ámbito ibérico (Martín Vide, 2001, 2002), mientras que en latitudes altas dan buenos resultados (Linderson, 2001). Además, la consideración del día como unidad temporal aislada en las clasificaciones anteriores - sean manuales o automáticas - supone una simplificación excesiva de la realidad. Por ese motivo se muestran incapaces de captar la dinámica atmosférica, que se expresa en una evolución de los campos báricos y de geopotenciales continua en el tiempo, a lo largo de varias jornadas. 
En el presente trabajo se propone y se hace uso de una clasificación objetiva, u obtenida por procedimientos estadísticos, y dinámica, con la consideración del día anterior y el siguiente al analizado, propuesta recientemente por Fernández y Díaz (2003). Los tipos de esta clasificación, obtenidos mediante análisis multivariante a partir de 2 niveles, superficie y $500 \mathrm{hPa}$, son denominados Procesos Sinópticos Objetivos, o PSO. Las características y ventajas de la clasificación de Fernández y Díaz se ponen en evidencia al aplicarla a los meses de septiembre y octubre, y su utilidad, al explicar la distribución espacial de la precipitación en el citado bimestre.

\section{Datos, criterios y metodología empleada}

Se consideró, en primer lugar, la retícula formada con un paso de rejilla de $2,5^{\circ}$ inserta en la ventana delimitada por los paralelos $30^{\circ}$ y $50^{\circ} \mathrm{N}$ y los meridianos $20^{\circ} \mathrm{W}$ y $10^{\circ} \mathrm{E}$, para un total de 117 puntos (13 meridianos x 9 paralelos). Los variables primarias analizadas en estos puntos han sido la presión atmosférica en superficie y la altura geopotencial en el nivel de $500 \mathrm{hPa}$, a partir de la base de datos NCEP-NCAR, para el período 1975-1996 (fig.1). Por otra parte, se hizo uso de la base reticular de datos de precipitación diaria del Instituto Nacional de Meteorología para un total de 203 puntos de la Península Ibérica y las islas Baleares, en el mismo período temporal.

Se aplicó, a continuación, el programa de cálculo para la selección de los Procesos Sinópticos Objetivos, cuya metodología ha sido elaborada por Fernández y Díaz (2003). Aunque el lector puede encontrar detallado el desarrollo de este método de clasificación de patrones sinópticos en el trabajo citado, sus fundamentos descansan, muy resumidamente, en: 1) la inclusión simultánea de la presión en superficie y el geopotencial en $500 \mathrm{hPa}$; 2) la consideración de ternas de situaciones sinópticas, correspondientes a los días D-1, D y D+1; 3) la vinculación entre el proceso sinóptico y los estados locales del tiempo; 4) un procedimiento de clasificación iterativo que hace uso de una distancia entre ternas y de la función discriminante de Miller; y 5) la obtención de los campos promediados de presión en superficie y de $\mathrm{Z}$ en $500 \mathrm{hPa}$ para cada grupo, o PSO, obtenido. Ha de añadirse aquí que se ha tomado el criterio de no considerar aquellos PSO que aco-

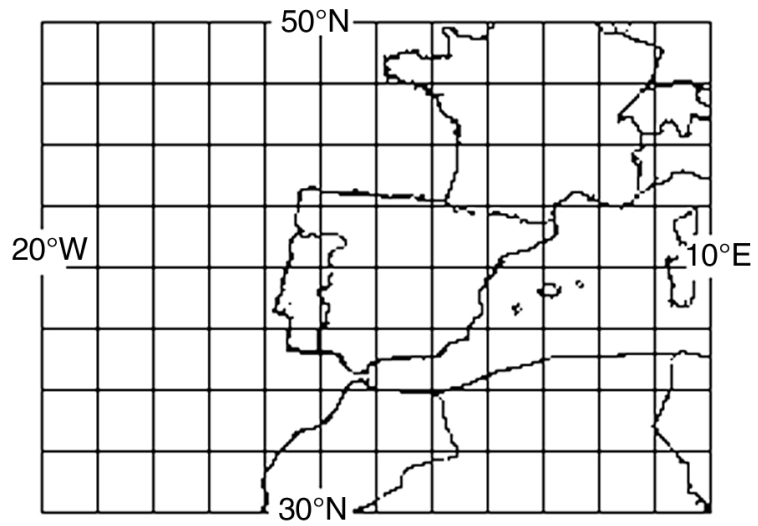

FIGURA 1. Área geográfica analizada y retículo usado. 
gen un porcentaje de casos inferior al $0,5 \%$ del total. Igualmente, a estos pequeños conjuntos de fechas descartadas en la clasificación ha de añadirse un reducido porcentaje de casos o días que pueden quedar excluidos en el proceso iterativo. Probablemente todos estos días no considerados, siempre en un porcentaje pequeño, constituyen casos extremos o singulares, que aportan poco al proceso de clasificación, aunque merezcan un análisis particular.

Finalmente, para cada uno de los puntos del retículo de la base de datos pluviométricos, y cada PSO, se calculó la probabilidad de ocurrencia de precipitación, a partir de la frecuencia relativa del fenómeno, así como la cantidad media o intensidad media diaria. Estos valores fueron expresados en mapas mediante interpolación, de manera que, al igual que ocurre con la presión en superficie y el geopotencial de $500 \mathrm{hPa}$, los pares de mapas pluviométricos se dibujan para los días D-1, D y D+1.

\section{Análisis y discusión de los principales resultados}

\subsection{Estadística de los PSO del bimestre analizado}

La selección de los PSO para el bimestre septiembre-octubre, durante el período 19751996, ha dado 20 tipos distintos. Ordenados y numerados según su frecuencia de aparición (cuadro 1), el PSO1 —el más frecuente — aparece en el 17,44\% de las fechas, mientras que el PSO20 - el más escaso-, sólo en el 0,52\%. La disminución de la frecuencia es cuasiexponencial negativa (figura 2). Los cuatro PSO más frecuentes acaparan prácticamente la mitad de los días $(49,34 \%)$ y los diez primeros el $80 \%$ (80,4\%). Inversamente, el período de retorno de los PSO, expresado en días, crece con rapidez a medida que disminuye su frecuencia (figura 2). Así, mientras el PSO1 se presenta, en promedio, más de 10 veces en el bimestre (período de retorno de 5,7 días), el PSO20 lo hace tan sólo una vez cada 3 años (período de retorno de 192,3 días). La regularidad en la disminución de las frecuencias y en el aumento de los períodos de retorno ilustrados en la figura 2, con un marcado aspecto de funciones exponenciales, negativa en el primer caso y positiva en el segundo, constituye un elemento que avala la propia metodología de los PSO. Esto es así, porque la persistencia de los patrones de la circulación atmosférica ha de primar unos pocos tipos frecuentes o normales, frente a un número relativamente alto de tipos poco probables o incluso excepcionales.

\subsection{Ventajas y potencialidades de los PSO}

Una vez realizada la aplicación al bimestre de comienzos de otoño, van quedando en evidencia algunas de las ventajas del procedimiento de los PSO y de sus potencialidades en la clasificación de situaciones sinópticas. En primer lugar, tal como se ha visto en el cuadro 1, el porcentaje de casos no asimilables a ninguno de los 23 PSO es de apenas un 1\%, lo que reduce muy notablemente el porcentaje de días indeterminados, inclasificables o de muy difícil clasificación, de cualquier procedimiento subjetivo en el ámbito mediterráneo. Incluso la clasificación de Jenkinson y Collison deja un apreciable número de fechas bajo esa categoría cuando se aplica a la Península Ibérica (Spellman, 2000).

La clasificación de los PSO de Fernández y Díaz (2003) conjuga la influencia de la presión atmosférica en superficie y la altura geopotencial correspondiente a los $500 \mathrm{hPa}$ como parte de un proceso integrado en el tiempo. La consideración de un nivel de la troposfera 
Cuadro 1

NÚMERO DE CASOS, FRECUENCIA RELATIVA, PERÍODO DE RETORNO $Y$ OTROS PARÁMETROS ESTADÍSTICOS DE LOS PSO PARA EL BIMESTRE SEPTIEMBRE-OCTUBRE (PERÍODO 1975-1996)

\begin{tabular}{|c|c|c|c|}
\hline PSO & $\boldsymbol{N}^{\boldsymbol{o}}$ casos & Frec. rel. (\%) & Per. Retorno (días) \\
\hline 1 & 234 & 17,44 & 5,7 \\
2 & 197 & 14,68 & 6,8 \\
3 & 119 & 8,87 & 11,3 \\
4 & 112 & 8,35 & 12,0 \\
5 & 99 & 7,38 & 13,6 \\
6 & 91 & 6,78 & 14,7 \\
7 & 69 & 5,14 & 19,5 \\
8 & 63 & 4,69 & 21,3 \\
9 & 52 & 3,87 & 25,8 \\
10 & 43 & 3,20 & 31,3 \\
11 & 42 & 3,13 & 31,9 \\
12 & 37 & 2,76 & 36,2 \\
13 & 29 & 2,16 & 46,3 \\
14 & 25 & 1,86 & 53,8 \\
15 & 24 & 1,79 & 55,9 \\
16 & 22 & 1,64 & 61,0 \\
17 & 22 & 1,64 & 61,0 \\
18 & 21 & 1,56 & 64,1 \\
19 & 11 & 0,82 & 122,0 \\
20 & 7 & 0,52 & 192,3 \\
\hline Total casos: 1342 & & & \\
\hline Chi (Dist(k)): 37 & & & \\
\hline Casos clasificados: 1319 & & & \\
\hline Malahos clasificados: 98,286 & & & \\
\hline
\end{tabular}

media (o superior), además del análisis en superficie, es imprescindible en el ámbito subtropical al que pertenece mayormente la España peninsular y las Baleares. Aquí los mecanismos de la troposfera media y alta tiene un peso decisivo en los tipos de tiempo, y en particular, en el comportamiento pluviométrico. La configuración sinóptica en superficie está falta de la información necesaria para llevar a cabo un proceso de clasificación coherente y representativo de los procesos atmosféricos, como ya asumieron la mayoría de las clasificaciones subjetivas más conocidas en el ámbito de España. Sobre éstas la clasificación basada en los PSO tiene la gran ventaja de asumir la evolución temporal, es decir, el propio concepto de proceso dinámico y variable en el tiempo. Esto permite, como se verá en el subapartado siguiente, discriminar situaciones sinópticas aparentemente similares en la ventana temporal del día D — clasificables en una misma categoría de las clasificaciones 

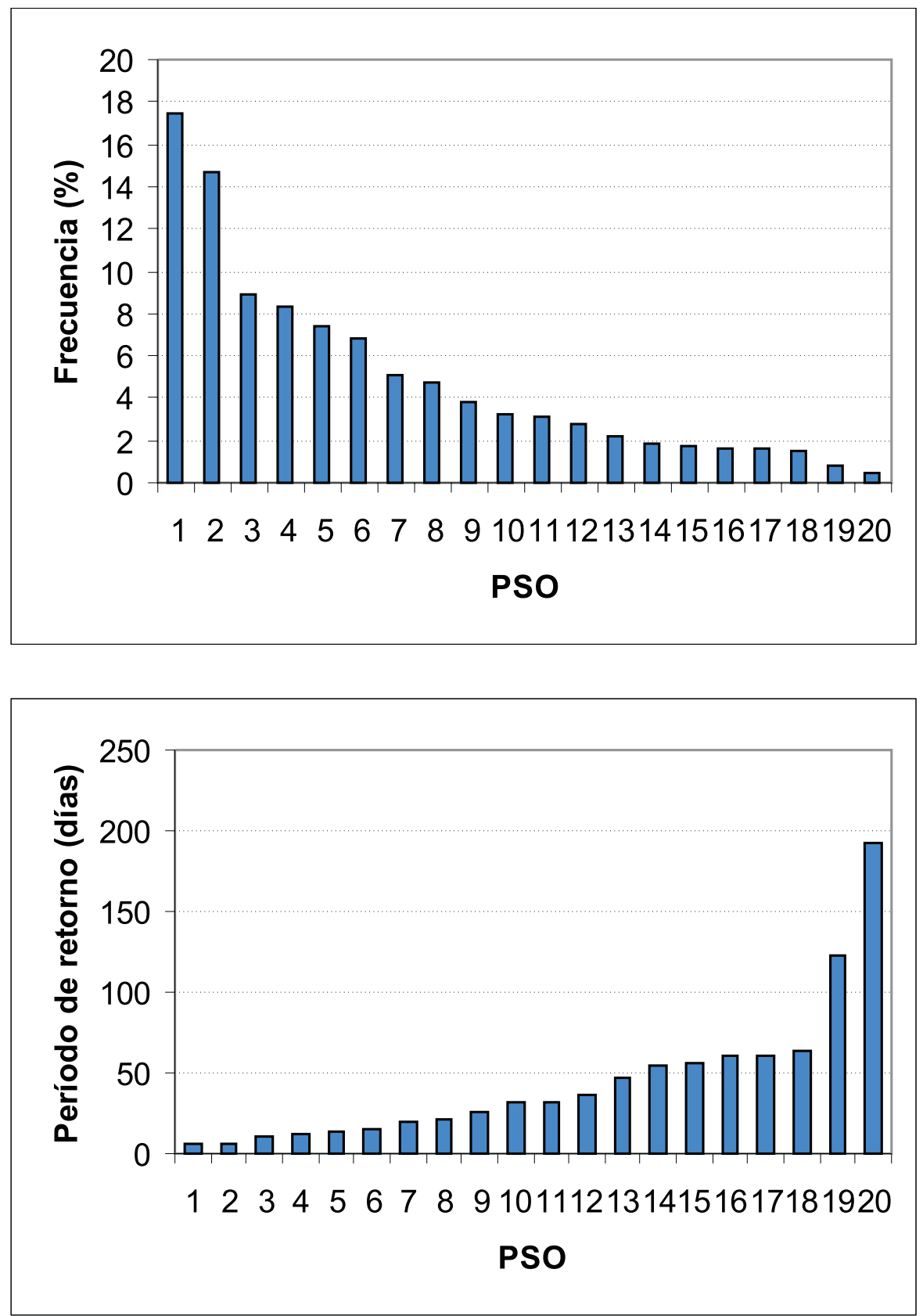

FIGURA 2. Frecuencia relativa (\%) y período de retorno (días) de cada uno de los PSO del bimestre septiembre-octubre (1975-1996). 
subjetivas u objetivas-, pero sustancialmente diferentes en su evolución temporal, por lo que constituyen PSO distintos.

\subsection{Características de los PSO y distribución espacial de la precipitación}

A continuación se presentan, en las figuras 3 a 22, el mapa de presión en superficie y la topografía de $500 \mathrm{hPa}$ de los $20 \mathrm{PSO}$ obtenidos para el bimestre otoñal y el período analizados, junto con la distribución espacial de la probabilidad y la cantidad media de la precipitación, describiéndose brevemente.

Proceso 1 (figura 3): Situación sinóptica que conlleva una marcada estabilidad atmosférica, por la configuración anticiclónica en altura. El tálveg (surco) en superficie que desde el norte de África apunta hacia la Península Ibérica, de carácter térmico, junto con la configuración en altura, permite afirmar que se trata de una situación típicamente estival. Septiembre tiene en un apreciable porcentaje de sus fechas, en especial de las dos primeras decenas, un carácter veraniego.

Proceso 2 (figura 4): La presencia de una vaguada en altura al oeste de la Península Ibérica y la retirada de la dorsal anticiclónica en superficie da lugar a un aumento de la probabilidad de precipitación en el norte y el este, en esta última área asociado a la presencia de un Mediterráneo caldeado y a flujos débiles del citado mar.

Proceso 3 (figura 5): Los flujos superficiales de componente este (de nordeste a sudeste) en la fachada mediterránea de la Península Ibérica y Baleares unidos a la circulación ciclónica en $500 \mathrm{hPa}$ sobre la cuenca mediterránea pueden dar lugar a precipitaciones de notable intensidad y cuantía en el golfo de Valencia y Baleares.

Proceso 4 (figura 6): La circulación de alto índice en $500 \mathrm{hPa}$ y los flujos de componente oeste en superficie en la mitad norte de la Península Ibérica favorecen pluviométricamente el cuadrante noroccidental. La probabilidad de ocurrencia de precipitación en Galicia, bien expuesta a los flujos húmedos atlánticos, es muy elevada.

Proceso 5 (figura 7): Buena parte del centro y del cuadrante suroccidental peninsular reciben su mayores inputs pluviométricos bajo una configuración del suroeste, aquí bien reflejada por la disposición de las isohipsas en $500 \mathrm{hPa}$. El mapa de superficie, poco definido, delata, no obstante, presiones poco altas en el área del golfo de Cádiz-Canarias-Azores.

Proceso 6 (figura 8): Situación que constituye un magnífico ejemplo del carácter esencialmente dinámico de la metodología empleada. La advección zonal en altura del día D-1 da paso a una dorsal anticiclónica en el D+1, a la par que el anticiclón de las Azores en superficie se expande hacia la Península Ibérica. En correspondencia con ello la probabilidad de lluvia disminuye con claridad en el país, quedando casi relegada a la cordillera Cantábrica y macizo Galaico, en forma de precipitación orográfica.

Proceso 7 (figura 9): Las condiciones progresivamente anticiclónicas en superficie y el mantenimiento de un buen flujo zonal en altura producen una clara diferenciación pluviométrica entre las mitades norte y sur peninsular. Este proceso presenta semejanzas con el anterior en el día $\mathrm{D}$, pero su evolución es diferente, lo cual es detectado por el método.

Proceso 8 (figura 10): La acusada vaguada submeridiana en $500 \mathrm{hPa}$ y los flujos de componente nordeste en superficie revierten en una apreciable probabilidad de precipitación en el norte y el este peninsular, y, en especial, en Baleares. La situación es plenamente otoñal, con notable descenso térmico.

Proceso 9 (figura 11): La situación supone la aproximación de una depresión septentrional y la llegada final de una masa de aire polar procedente del noroeste, que favorece 
pluviométricamente a las regiones más próximas y mejor expuesta a los flujos de aquella dirección, dejando, por el contrario, a salvo, el sudeste peninsular.

Proceso 10 (figura 12): Clara advección septentrional con la traslación de una depresión desde el noroeste del continente europeo hacia los Alpes. El norte de España y el área mediterránea pueden registrar cantidades de precipitación estimables.

Proceso 11 (figura 13): La Península Ibérica queda en la rama ascendente u oriental de una gran vaguada atlántica, por lo que la probabilidad de precipitación es alta, salvo en el sudeste.

Proceso 12 (figura 14): Situación típicamente atlántica, de origen relativamente parecido al de otros procesos ya descritos.

Proceso 13 (figura 15): Situación de evolución muy rápida. Las isohipsas con curvatura ciclónica en $500 \mathrm{hPa}$, en el día D-1, tienden a la curvatura anticiclónica, en el D+1, mientras que la advección del noroeste en superficie, en el día D-1, da paso a la entrada del anticiclón de las Azores, en el D+1. Progresiva reducción de las precipitaciones.

Proceso 14 (figura 16): Predominio de las condiciones depresionarias a todos los niveles. Situación de clara inestabilidad. Precipitaciones en prácticamente todas las regiones.

Proceso 15 (figura 17): Situación de rápida evolución y filiación atlántica, con ciertas similitudes con el proceso 16 en el día $\mathrm{D}$, pero de desarrollo muy diferente.

Proceso 16 (figura 18): Depresión dinámica al norte de la Península Ibérica, asociada a una elevada probabilidad de ocurrencia de precipitación en buena parte del territorio.

Proceso 17 (figura 19): Los senos y vaguadas en altura y superficie lo asemejan en alguna medida al proceso 16. Las consecuencias pluviométricas en el día D+1 son similares.

Proceso 18 (figura 20): Situación de flujos de componente este en superficie y «gota fría», o depresión fría o depresión aislada en niveles altos (DANA), en altura hacia el oeste peninsular. El borde oriental de la citada depresión, coincidente con la vertiente mediterránea, alcanzada, además, por los flujos húmedos mediterráneos, es el de mayor actividad pluviométrica. No son raras precipitaciones torrenciales al sur de Valencia.

Proceso 19 (figura 21): Profundo meandro de la circulación superior coincidente con una depresión aproximándose al norte de España. El jet stream polar suele abrazar la Península Ibérica por las latitudes próximas a las del estrecho de Gibraltar. Precipitaciones abundantes en buena parte del país.

Proceso 20 (figura 22): Situación parecida a otras anteriomente descritas, pero con una evolución hacia condiciones de menor inestabilidad.

\section{Conclusiones}

- La aplicación de la metodología de los Procesos Sinópticos Objetivos (PSO) desarrollada por Fernández y Díaz (2003) a la Península Ibérica y las Baleares en el bimestre septiembre-octubre (período 1975-1996) identificó un total de 20 procesos. Su probabilidad de ocurrencia denota un decrecimiento rápido a partir de los procesos más frecuentes, seguido por una disminución gradual hasta los procesos más raros.

- Los PSO son capaces de poner en evidencia los tipos de tiempo característicos del bimestre otoñal analizado, al establecer el nexo entre las particularidades del proceso y la distribución de la probabilidad y la cantidad media de la precipitación en el área de estudio. 
- La sucesión de mapas de presión media en superficie junto con las topografías medias en $500 \mathrm{hPa}$ desde el día D-1 al D+1 caracterizan integralmente los PSO, especificando los rasgos identificadores más esenciales. Diversos PSO con situación sinóptica semejante en el día D son considerados diferentes por causa de una dinámica temporal distinta.

- En general, los PSO más frecuentes se corresponden con condiciones de tiempo más estable y fluctuaciones temporales relativamente pequeñas, mientras que los PSO menos frecuentes se muestran más dinámicos y asociados a situaciones de lluvias y tormentas.

\section{Agradecimientos}

Los autores quieren expresar su más sincero reconocimiento a D. Ángel Rivera Pérez, Jefe del Área de Predicción y Aplicaciones del Instituto Nacional de Meteorología, por haber facilitado la base reticular de precipitaciones diarias de España. Esta base ha permitido llevar a cabo investigaciones conjuntas relacionadas con la aplicación de la técnica de los análogos al pronóstico de precipitación y a la generalización de los PSO al ámbito de la Península Ibérica.

\section{Referencias bibliográficas}

CAPEL MOLINA, J.J. (2000): El clima de la península Ibérica, Barcelona, Ariel.

FERNÁNDEZ, A. y DÍAZ, Y. (2003): Catálogo de los procesos sinópticos en el archipiélago cubano, Cienfuegos, Centro Meteorológico Provincial, Imprenta GeoCuba, 170 pp.

FONT TULLOT, I. (1983): Climatología de España y Portugal, Madrid, Instituto Nacional de Meteorología.

GIL OLCINA, A. y OLCINA, J. (1997): Climatología general, Barcelona, Ariel.

JENKINSON, A.F. y COLLISON, B.P. (1977): «An initial climatology of gales over the North Sea». Synop. Climatol. Branch Memo., 62, Meteorological Office, Bracknell.

LINDERSON, M. (2001): «Objective classification of atmospheric circulation over Southern Scandinavia». International Journal of Climatology, 21, 155-169.

LINÉS, A. (1981): Perturbaciones típicas que afectan a la península Ibérica y precipitaciones asociadas, Madrid, Instituto Nacional de Meteorología.

MARTÍN-VIDE, J. (1991): Mapas del tiempo: fundamentos, interpretación e imágenes de satélite, Barcelona, Oikos-tau.

MARTÍN-VIDE, J. (2001): «Limitations of an objective weather-typing system for the Iberian peninsula». Weather, 56 (7), 248-250.

MARTÍN-VIDE, J. (2002): «Aplicación de la clasificación sinóptica automática de Jenkinson y Collison a días de precipitación torrencial en el este de España», En Cuadrat, Vicente y Saz, La información climática como herramienta de gestión ambiental, 123127, Universidad de Zaragoza y Asociación de Geógrafos Españoles.

SPELLMAN, G. (2000): «The application of an objective weather-typing system to the Iberian peninsula». Weather, 55, 375-385. 
Figuras 3 a 22. Presión en superficie y topografía de 500 hPa de los PSO, y cantidad media y probabilidad de precipitación asociadas en la España peninsular y Baleares.
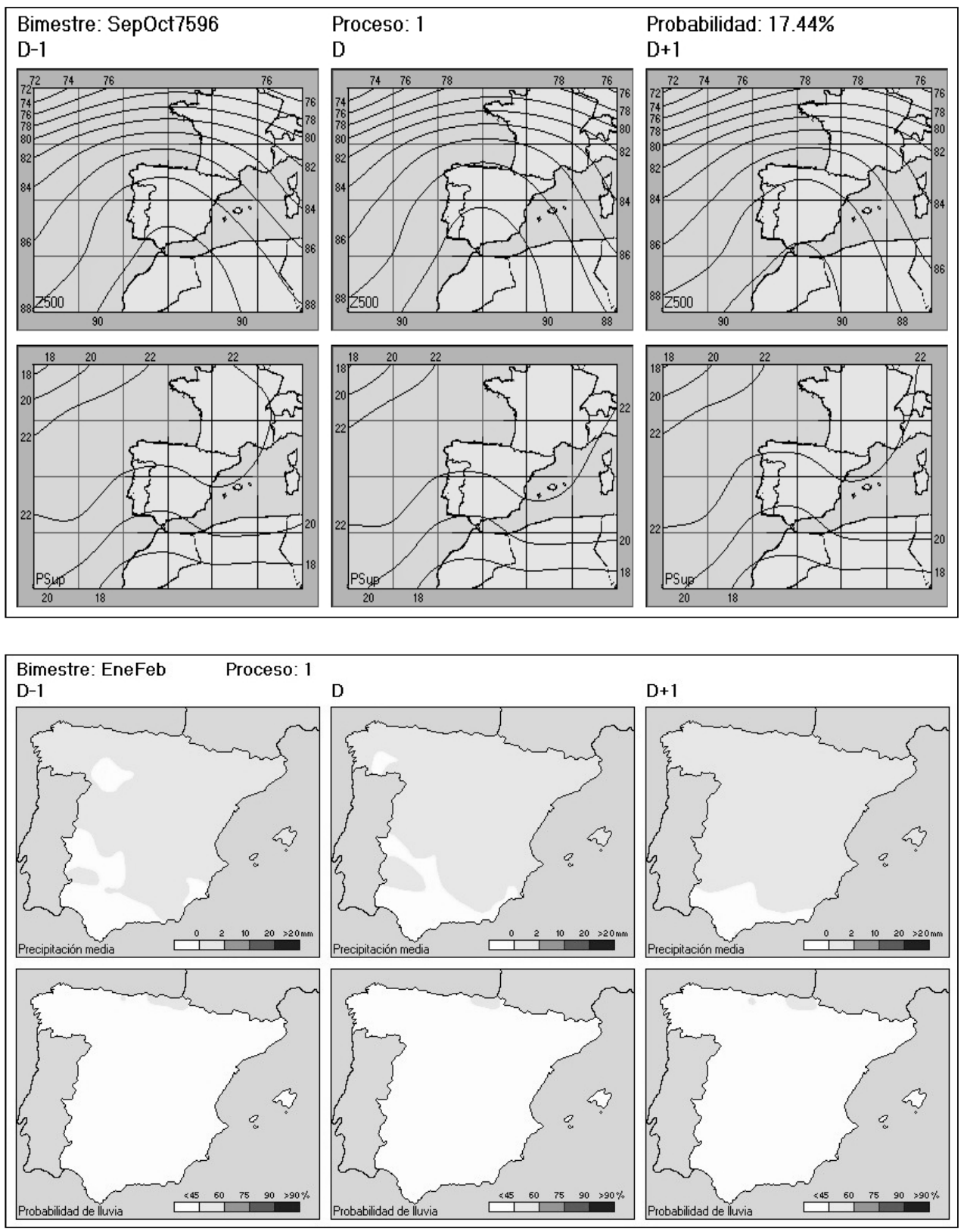

FIGURA 3. 

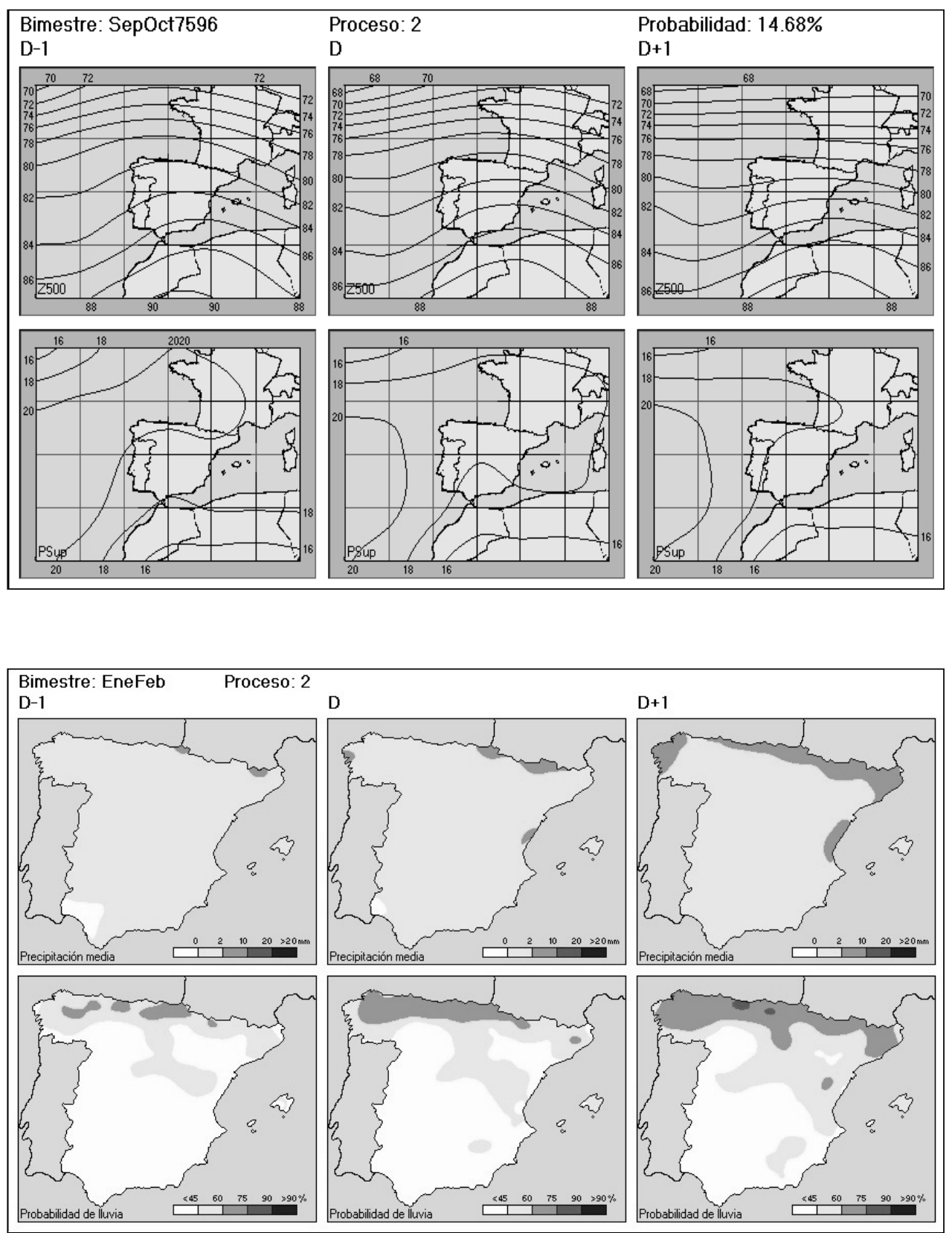

FIGURA 4. 

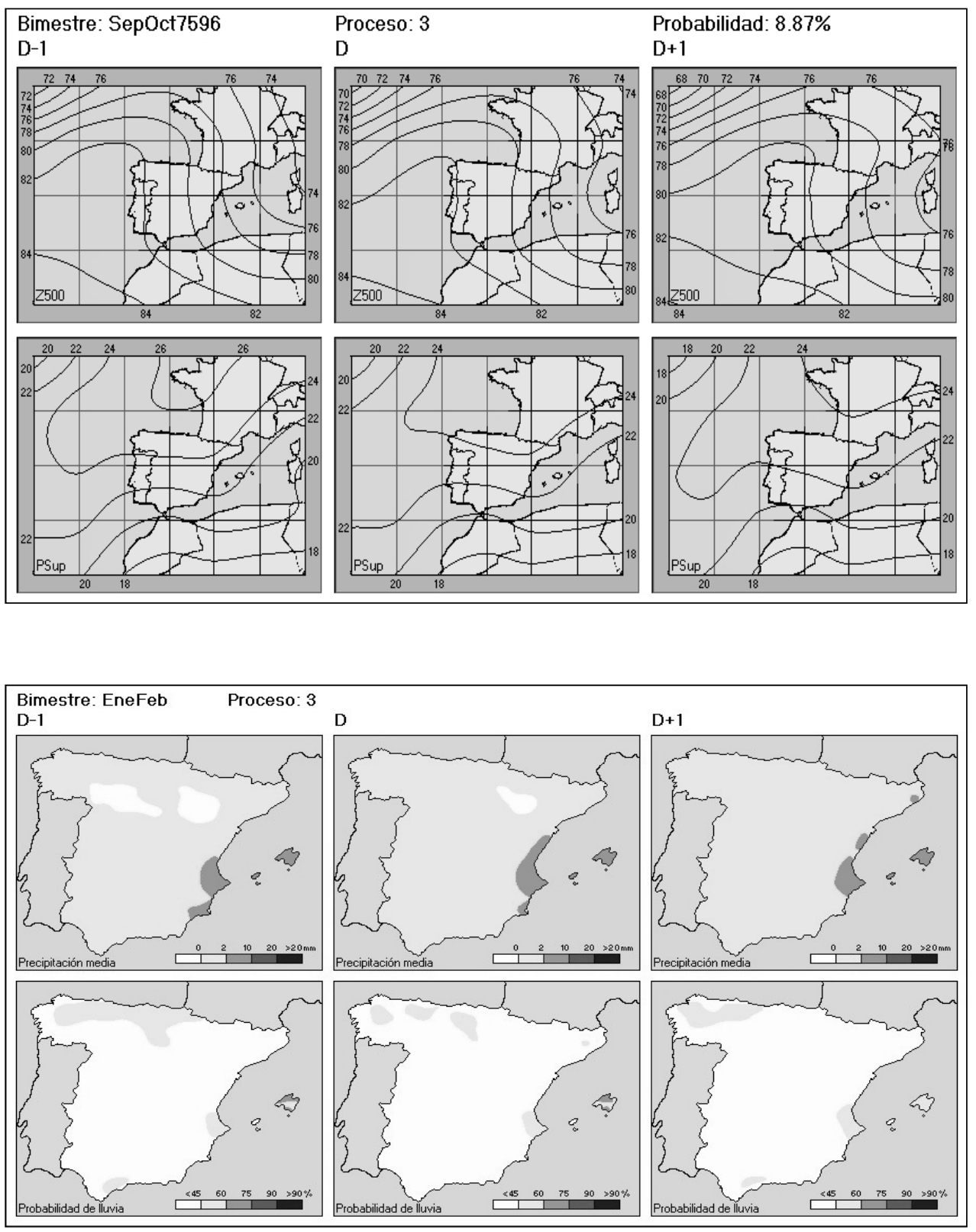

FIGURA 5. 

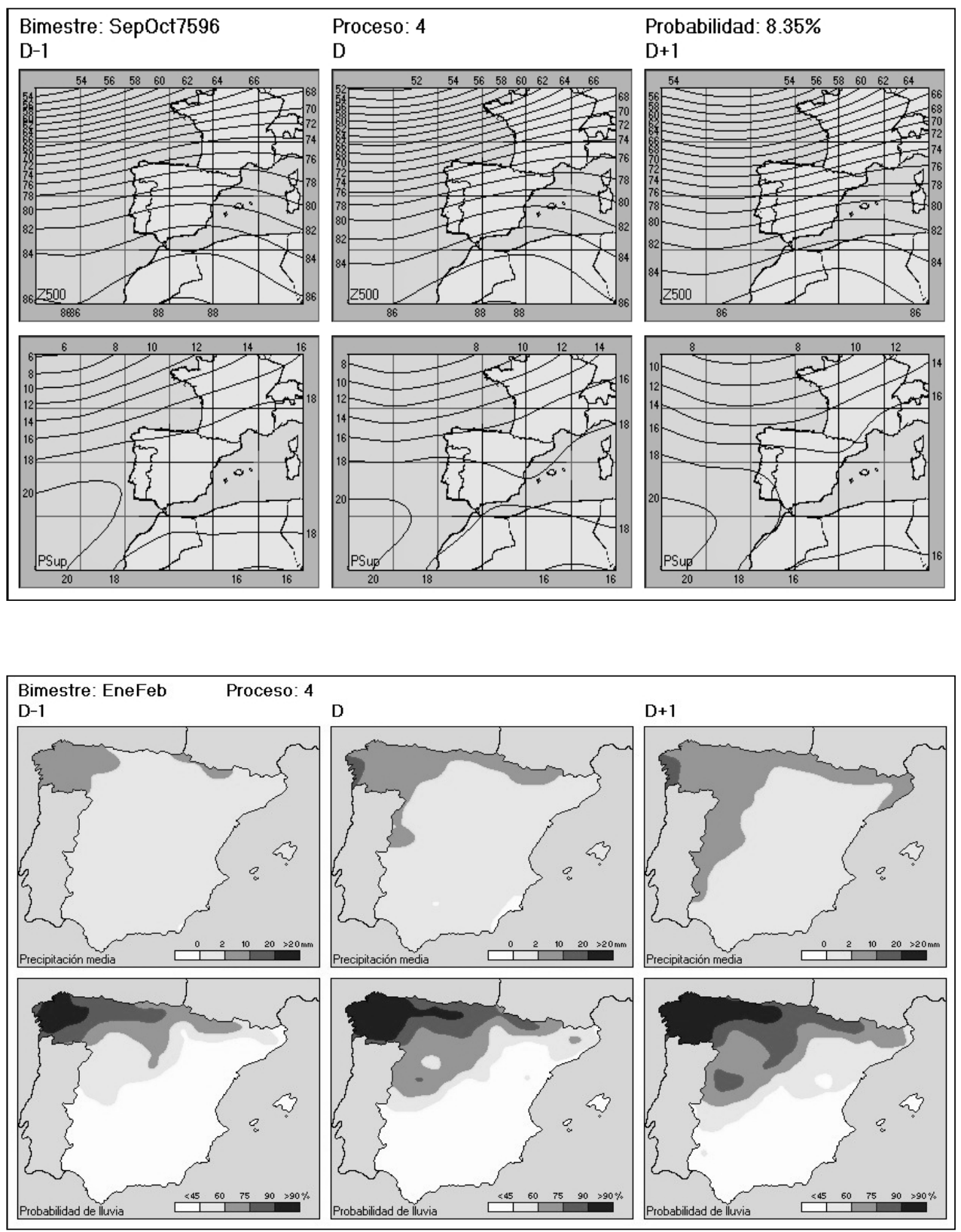

FIGURA 6. 

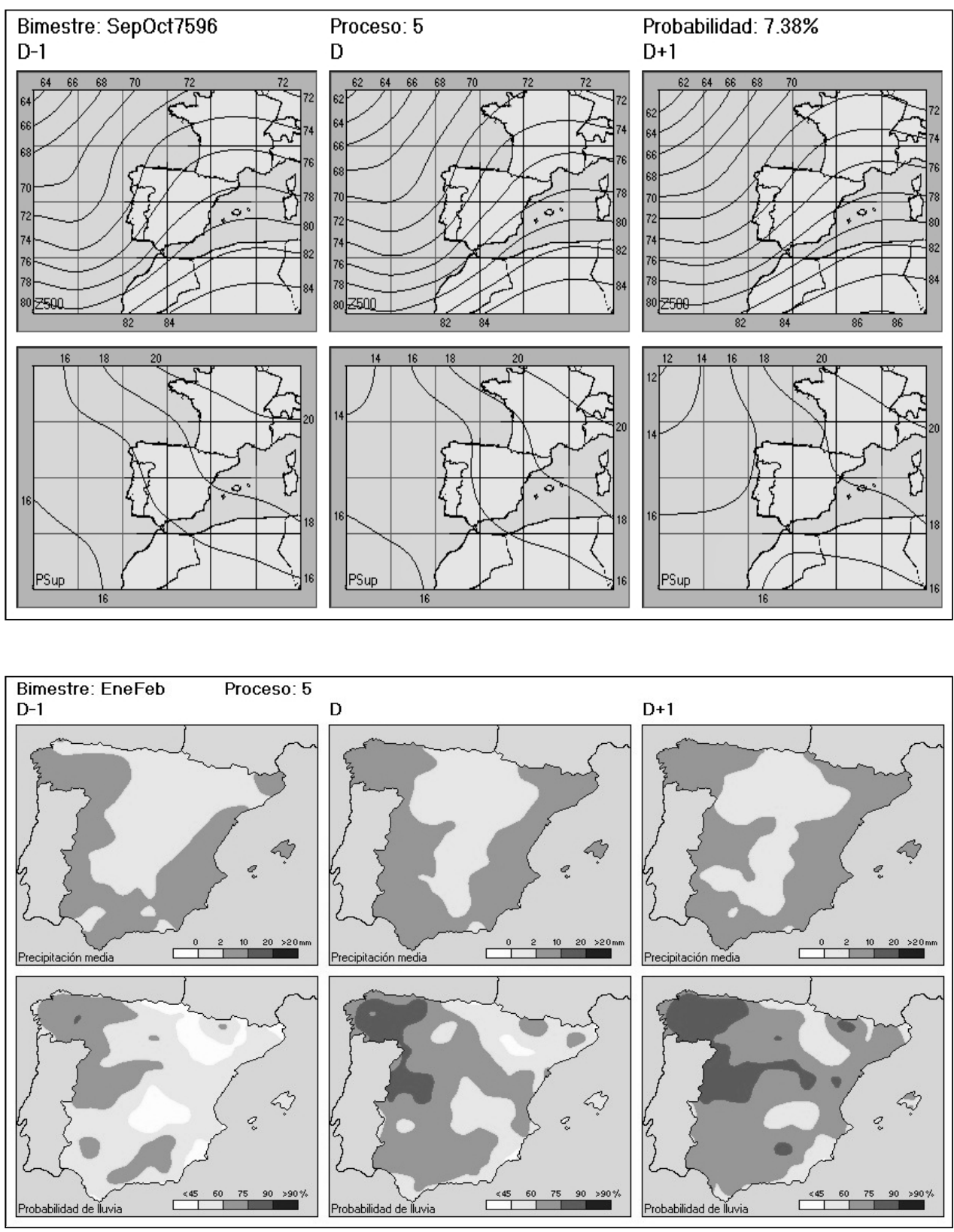

FIGURA 7. 

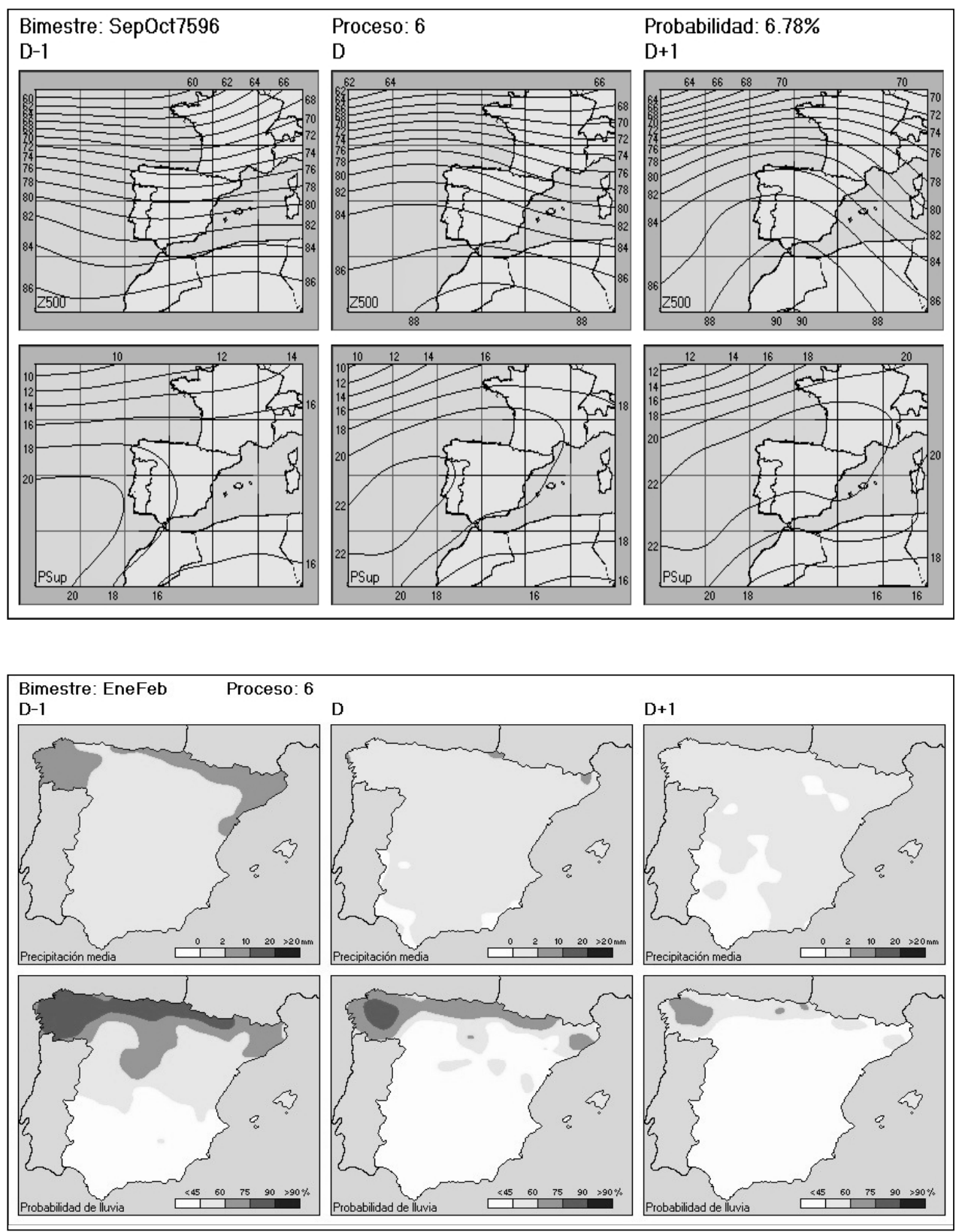

FIGURA 8. 



FIGURA 9. 

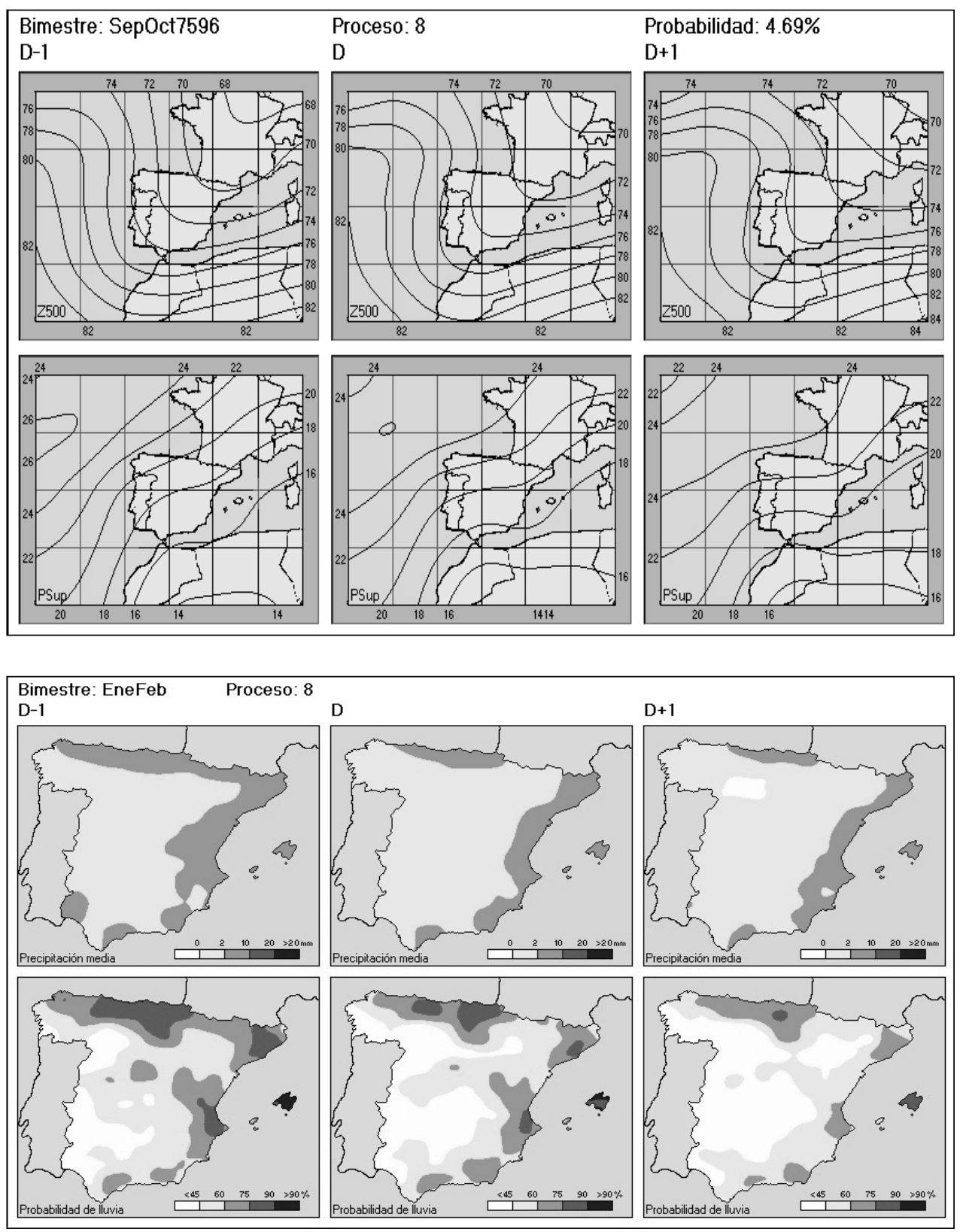

FIGURA 10. 

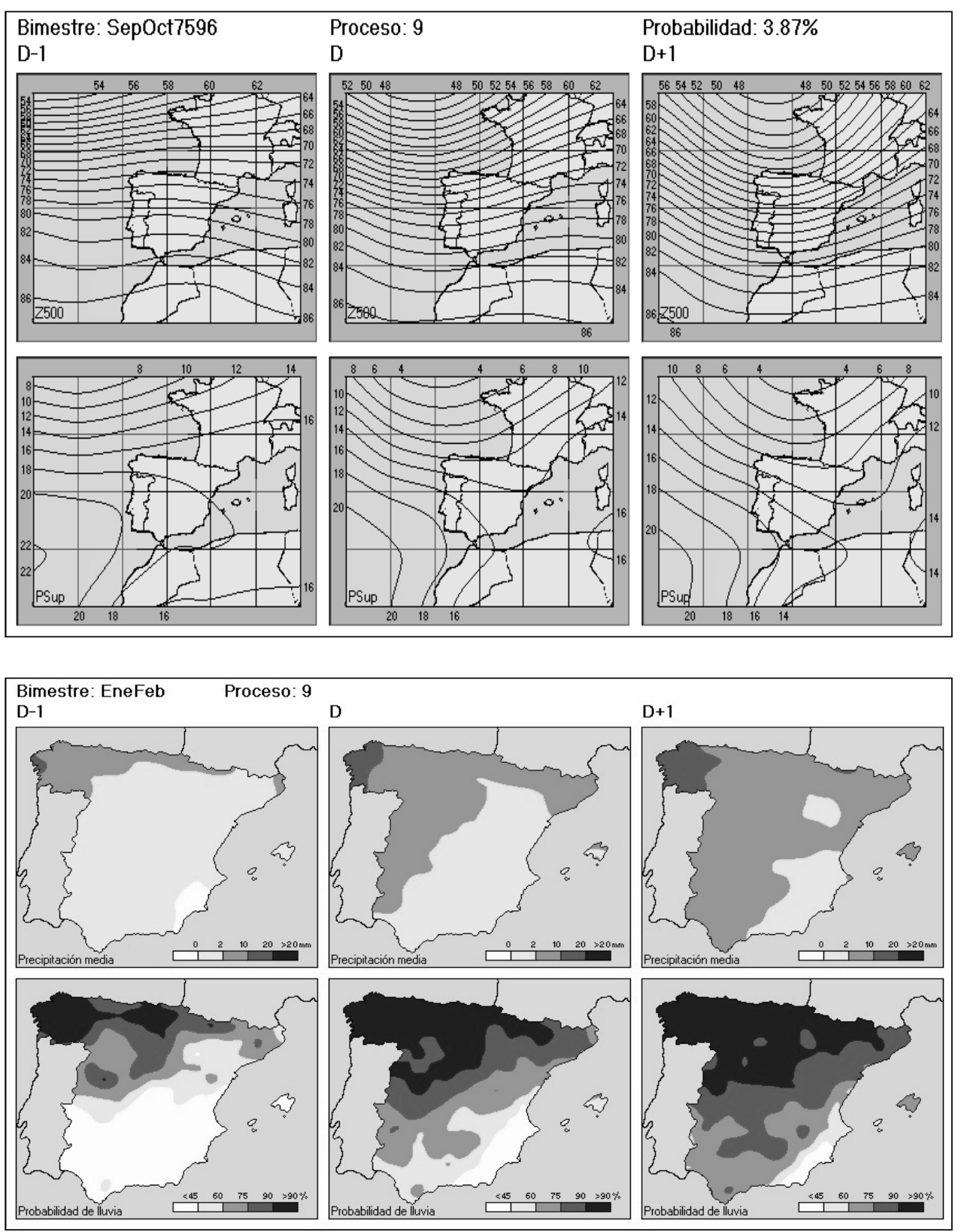

FIGURA 11. 

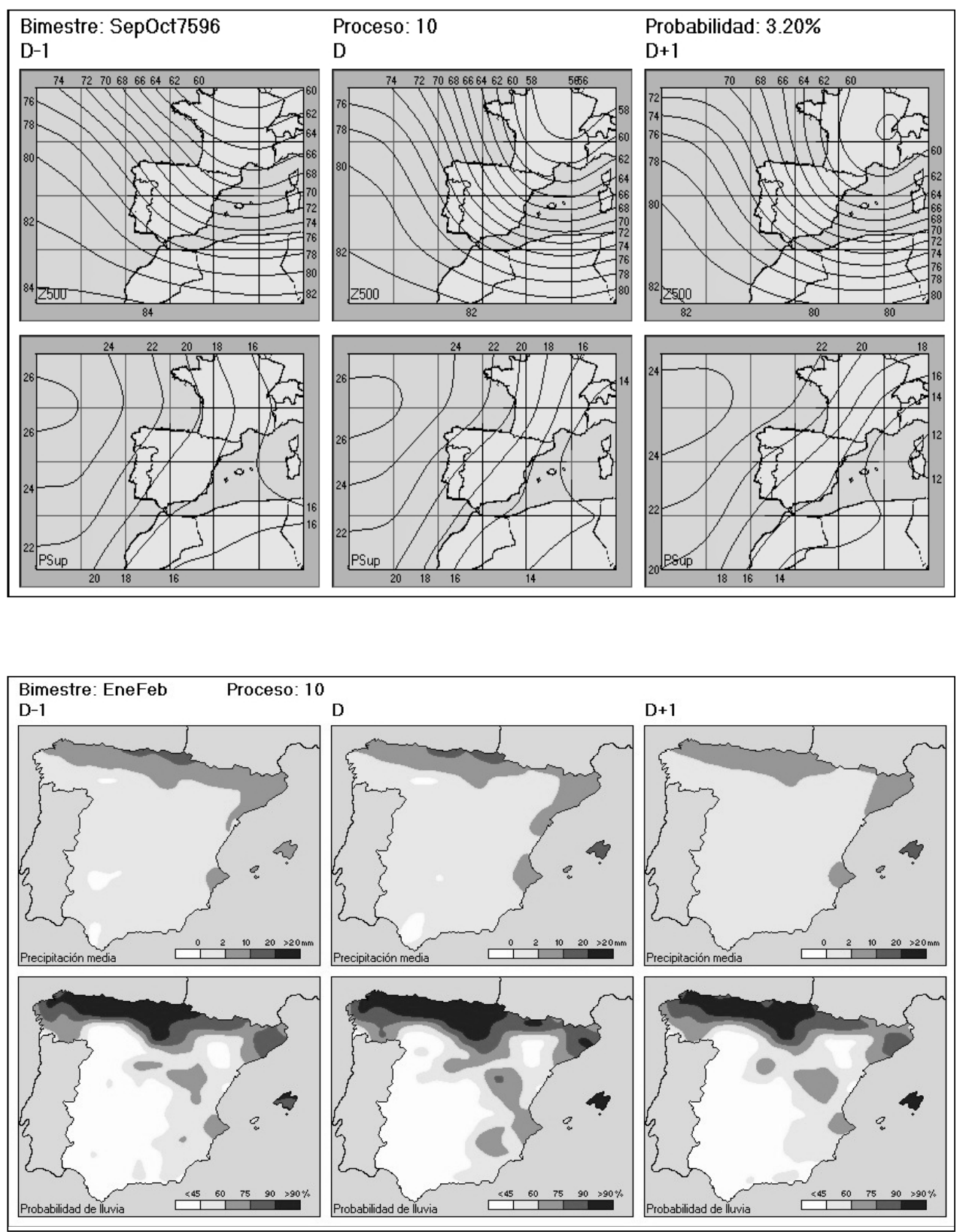

FIGURA 12. 

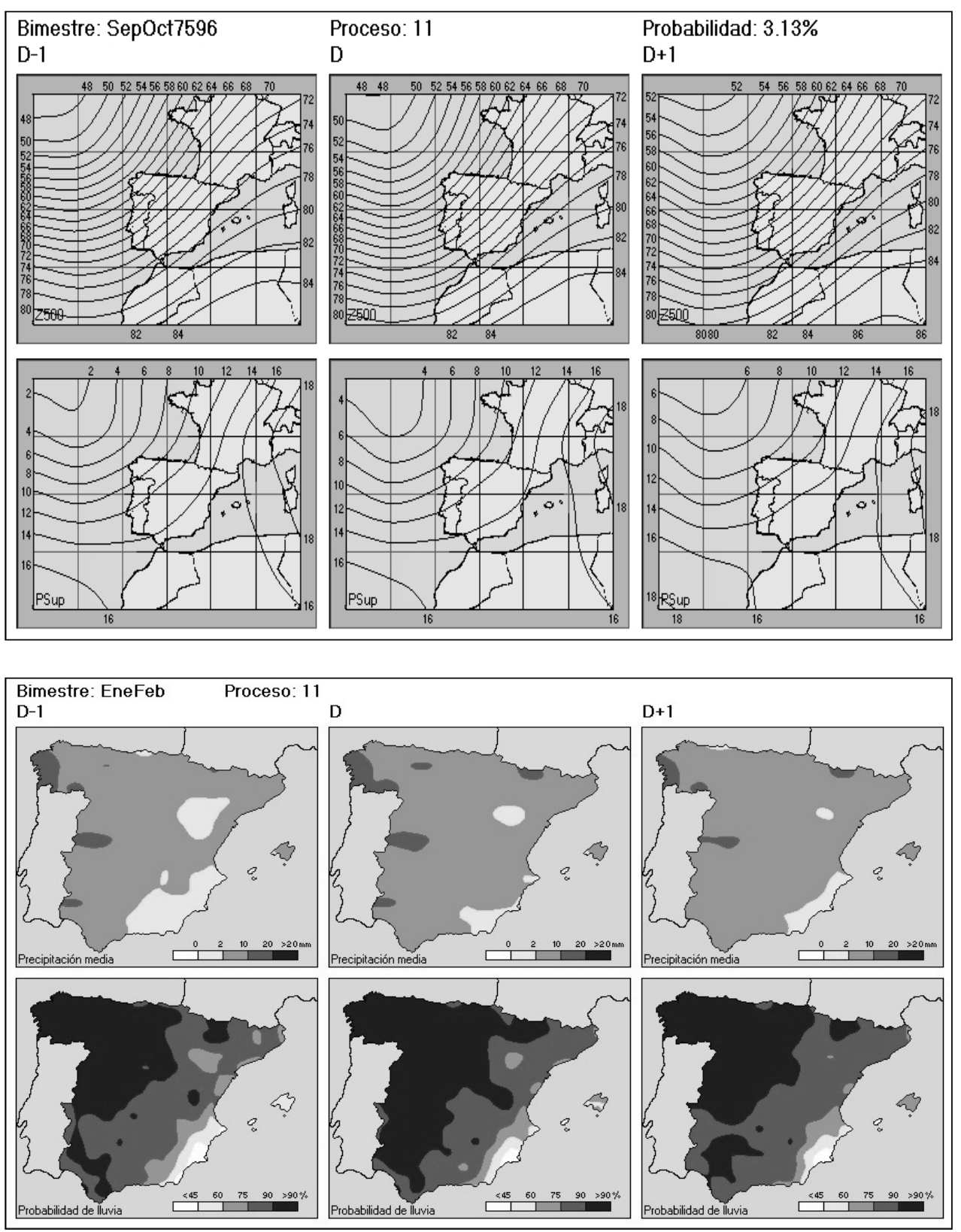

FIGURA 13. 

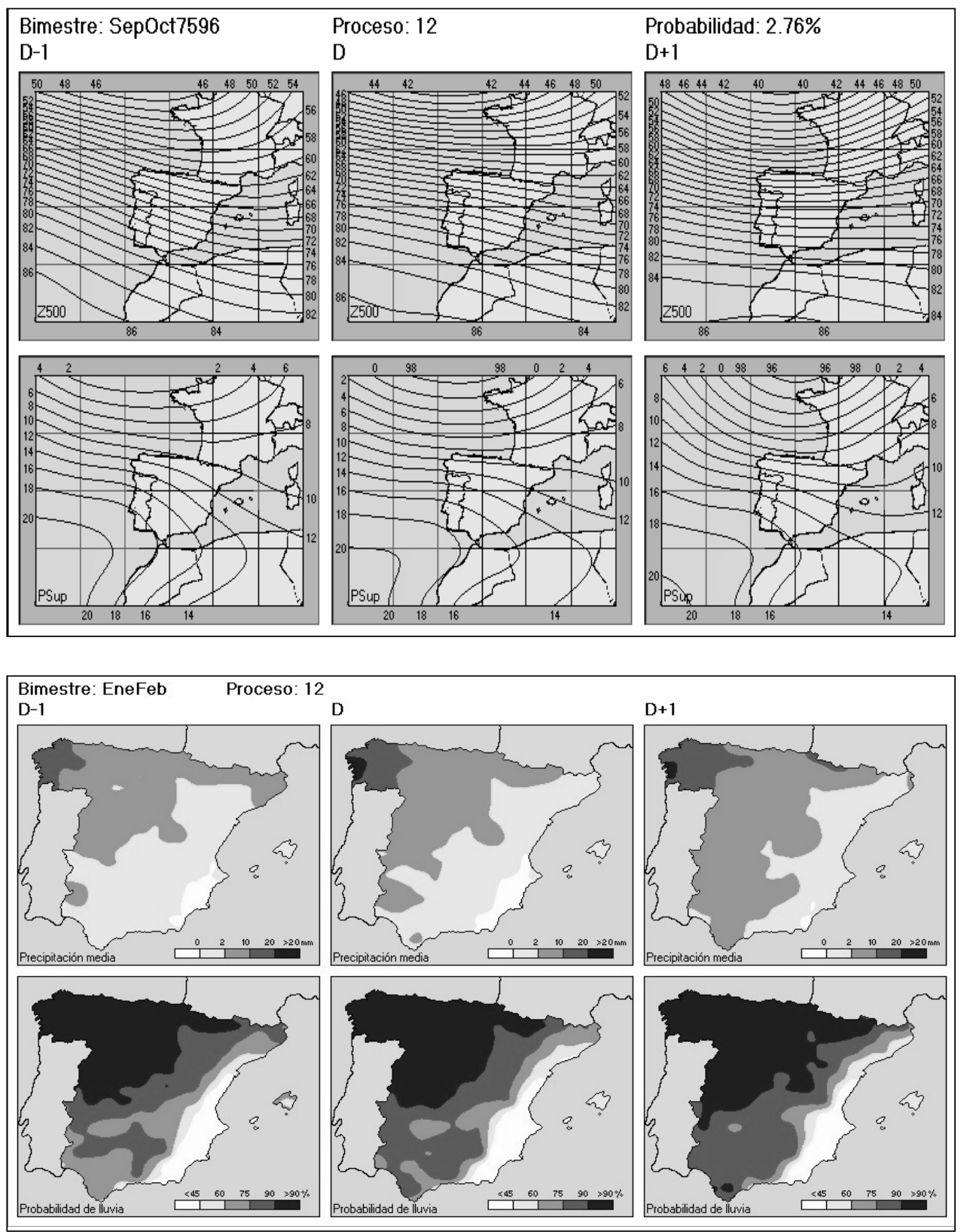

FIGURA 14. 

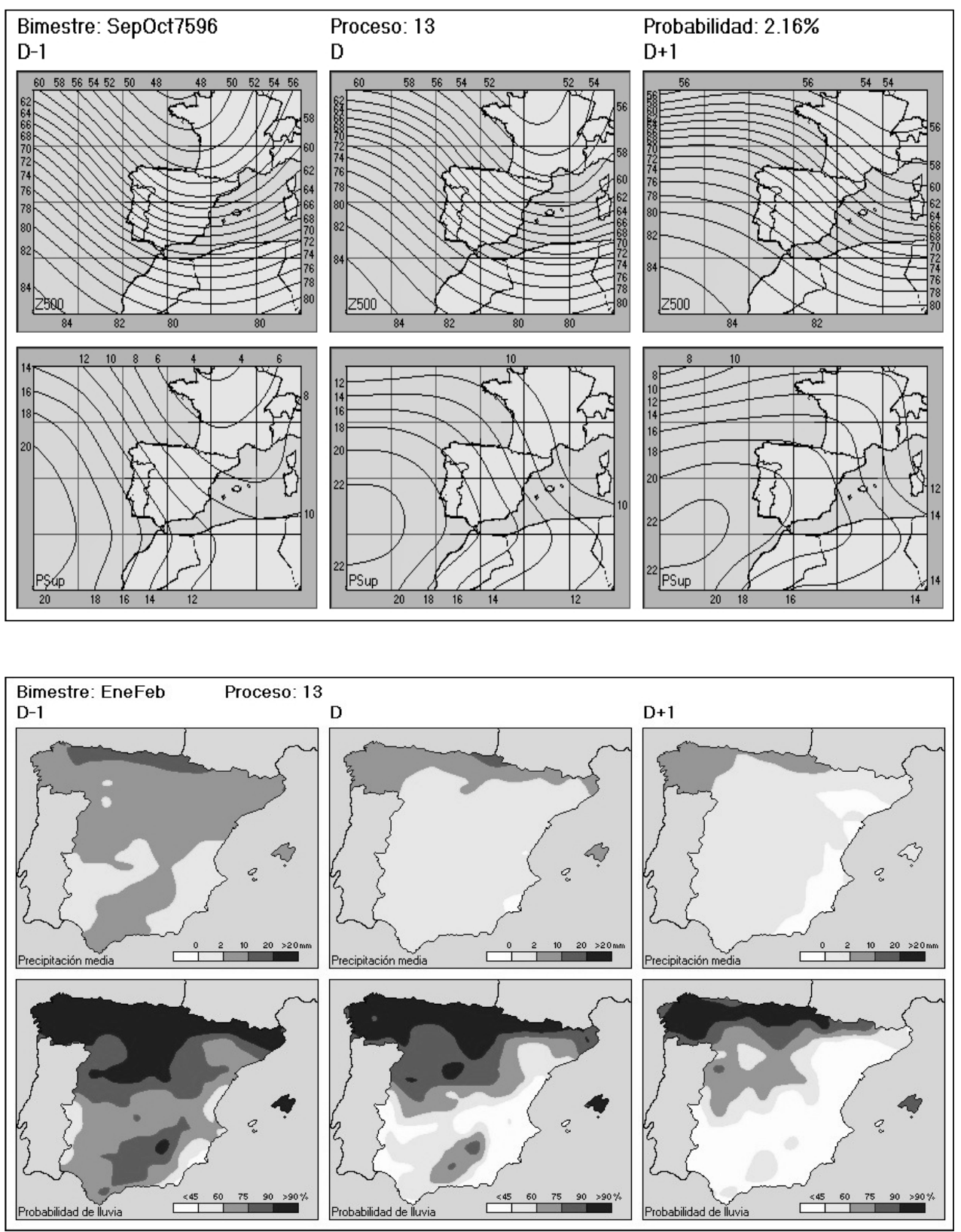

FIGURA 15. 

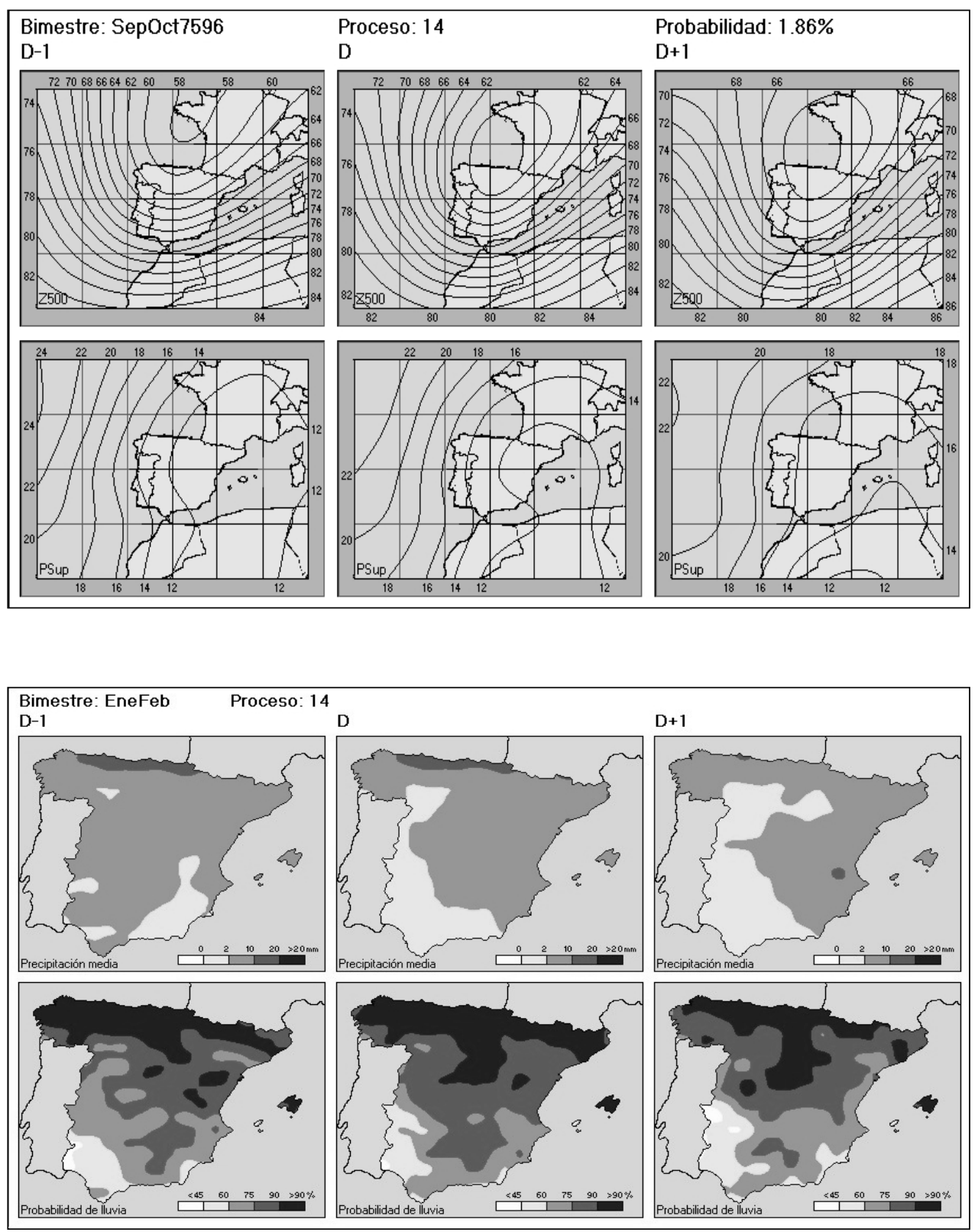

FIGURA 16. 

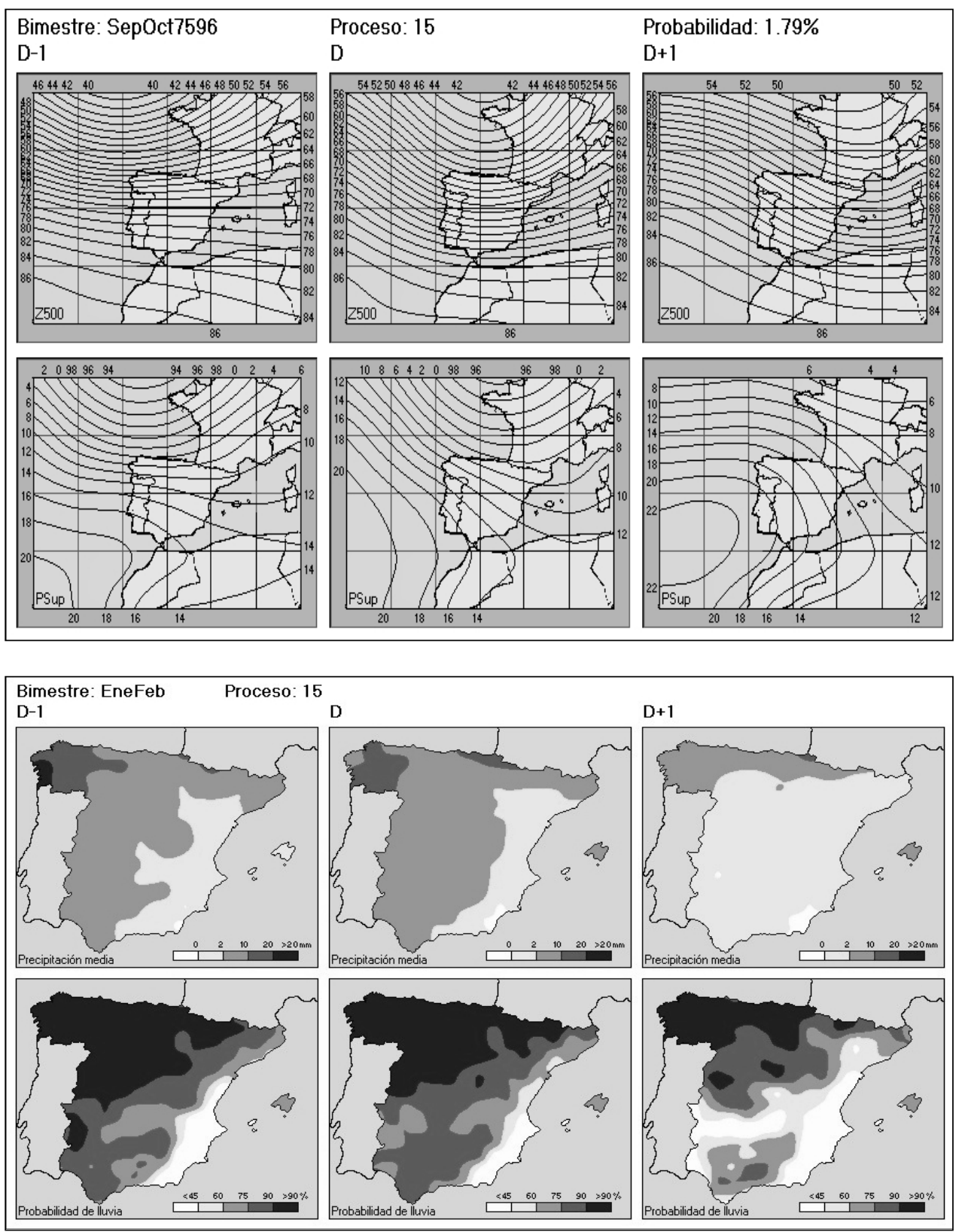

FIGURA 17. 



FIGURA 18. 

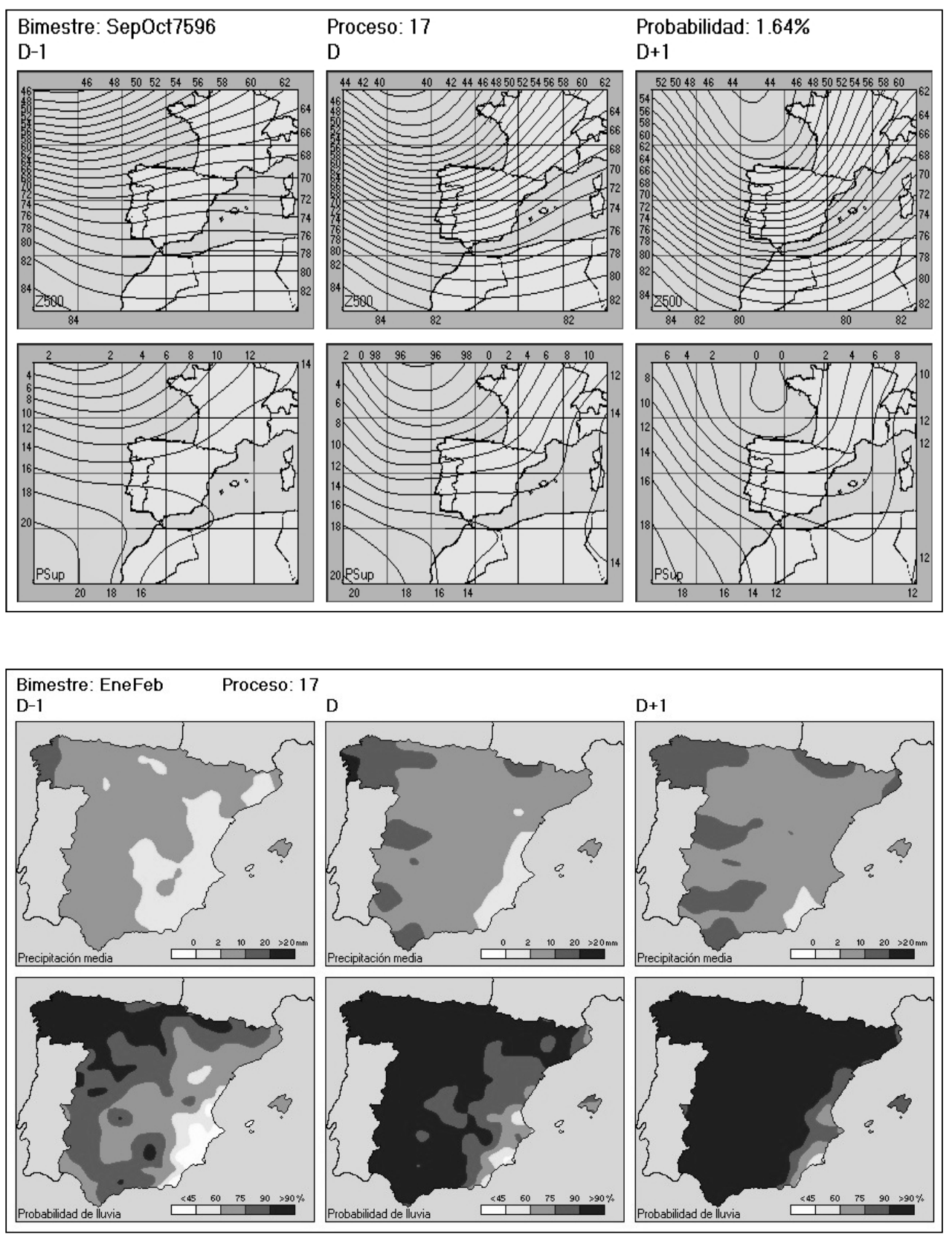

FIGURA 19. 

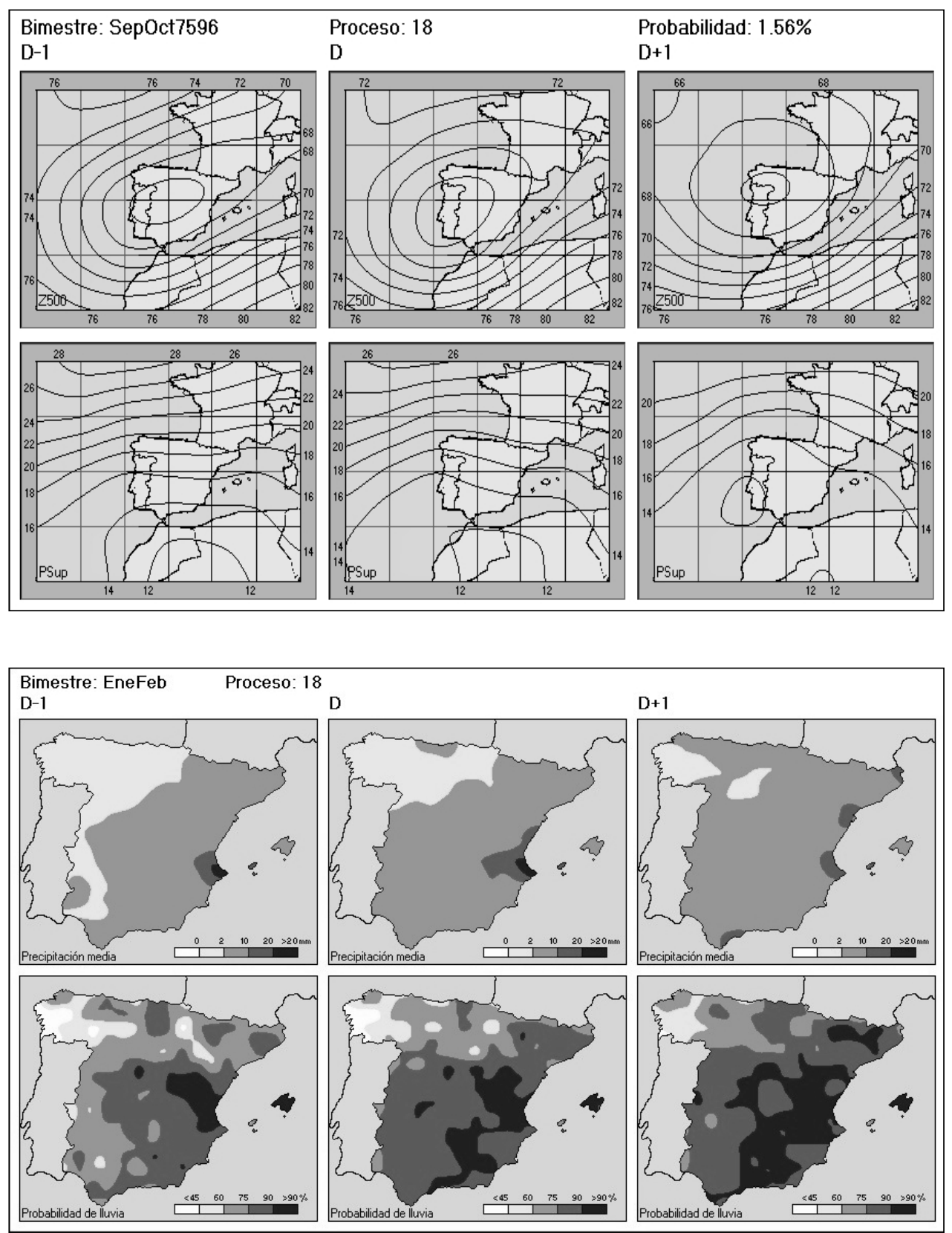

FIGURA 20. 

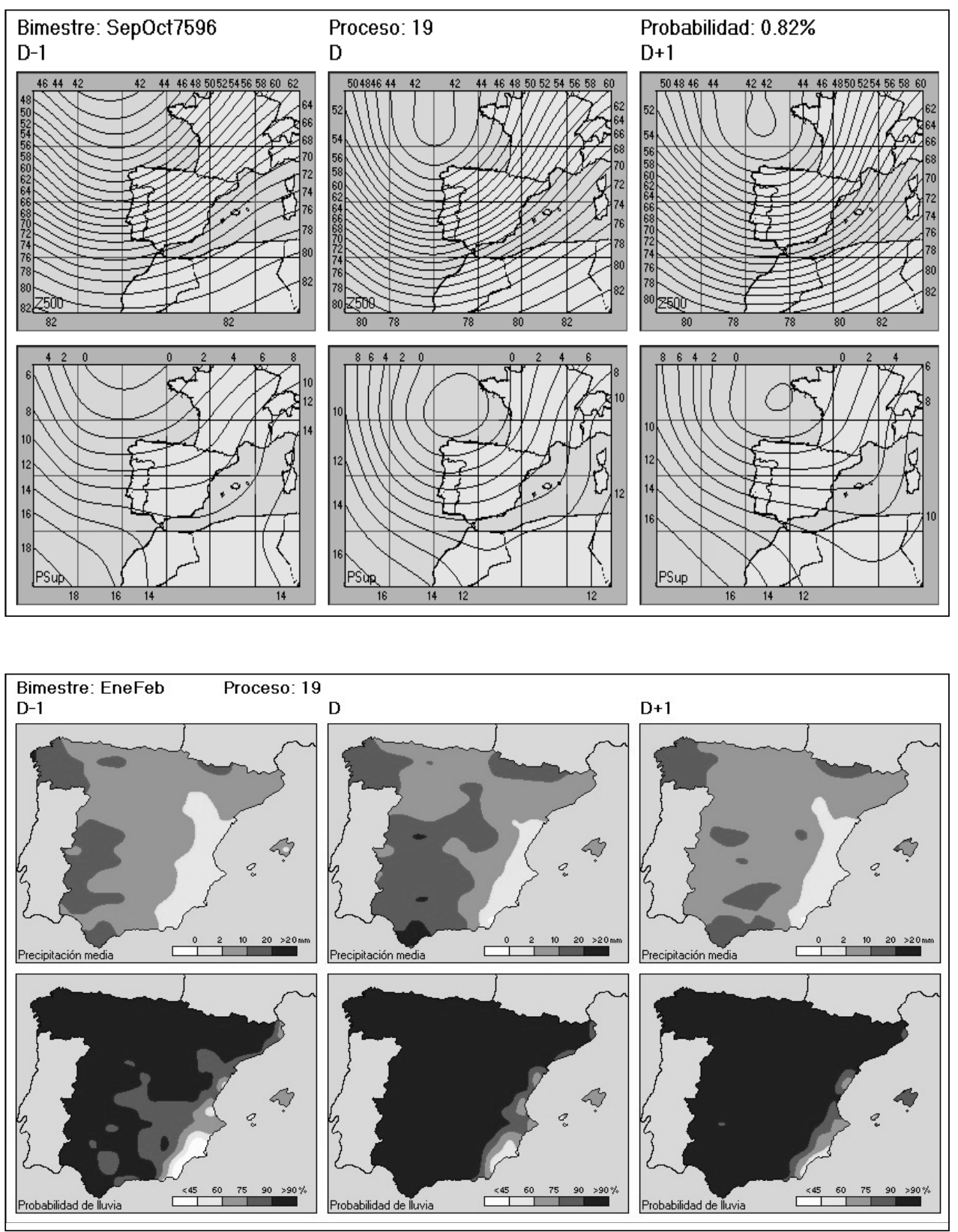

FIGURA 21. 

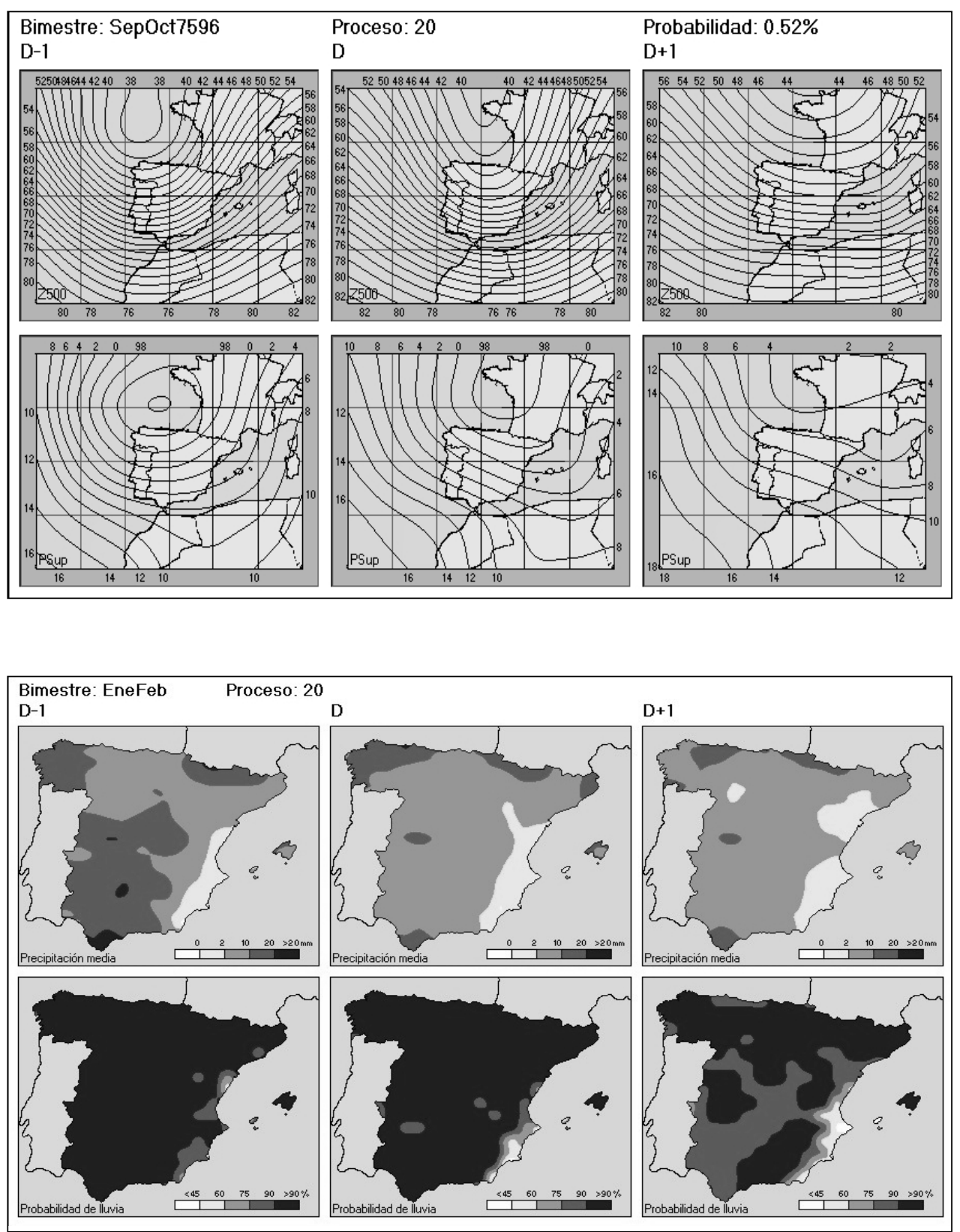

FIGURA 22. 
